\title{
Realidade Aumentada aliada aos Materiais Didáticos na Educação Básica
}

\author{
Reginaldo Gotardo, Jean-Jacques De Groote, Neli Volpini, Erica Stamato, \\ Paulo Dias, Thiago Almeida, Alexandre Bueno
}

\begin{abstract}
Resumo. Esse trabalho apresenta a utilização da Realidade Aumentada em jogos educacionais. Essa tecnologia torna possivel o aumento da interatividade de elementos educacionais para os usuários, criando diversas formas de incentivar o aprendizado. $O$ método final apresenta como resultados de aplicação prática a construção de ambientes virtuais para um aplicativo tendo como tema a coleta seletiva de lixo com roteiro interativo desenvolvido por educadoras ligadas ao projeto principal. A outra prática mostra os conceitos de semeadura de Girassóis. Ambos alinhados a materiais de apoio e complementação, especialmente desenvolvidos para sinergia no projeto.
\end{abstract}

\section{Introdução}

Esse trabalho apresenta uma Abordagem Educacional utilizando como recurso tecnológico a Realidade Aumentada para uso em escolas de Educação Básica. A Realidade Aumentada é a combinação do mundo real com o virtual promovendo interatividade em tempo real (Azuma, 1997). Esta combinação pode variar entre um ambiente mais próximo do virtual (Virtualidade Aumentada) ao mais próximo do real (Realidade Aumentada) (Milgram \& Kishino, 1994).

A utilização da Realidade Aumentada visa enriquecer os recursos e suportes pedagógicos e didáticos utilizados na construção do conhecimento (Yuen, YaoYuneyong, \& Johnson, 2013) (El Sayed, Zayed, \& Sharawy, 2011) (Viegas \& Silva, 2010).

O projeto envolveu a criação de jogos que permitam a sistematização dos conhecimentos e a problematização levando o aluno a buscar recursos mentais para a resolução dos problemas apresentados, não ficando restrito apenas a ações do tipo estímulo-resposta, ou apenas voltado aos aspectos estéticos e artísticos das imagens apresentadas. Tais aspectos são significativos e instigantes onde professor e aluno vão atuar e generalizar aprendizagens frente aos novos desafios.

O recorte temático inscreve-se na área de Ciências Naturais - Educação Ambiental e o público alvo são alunos em fase de alfabetização. A pesquisa é considerada inovadora, pois utiliza procedimentos tecnológicos como meio de compreensão aproximada da realidade virtual e global as quais caracterizam a contemporaneidade. Oferece também suporte tecnológico e didático aos agentes escolares viabilizando a formação docente de forma crítica e transformadora em espaços de análise e crítica do uso das TIC (tecnologias de informação e comunicação) na escola, de forma a inovar e fortalecer medidas educativas já existentes, possibilitando a inserção das crianças pequenas na temática ambiental, seja nas atividades em sala, bem como propondo ações no entorno da escola e dentro desse espaço (ver, julgar e agir). Esse suporte é apresentado através de materiais complementares na forma de livros 
impressos e digitais com dois formatos: formato para o aluno (com atividades) e o formato para o professor (com orientações).

No âmbito tecnológico foram investigadas técnicas especiais das áreas de visão computacional e reconhecimento de objetos para o desenvolvimento de algoritmos que permitam que informações do mundo real sejam reconhecidas automática e rapidamente por computadores.

\section{Realidade Aumentada e Desenvolvimento de Aplicações}

Para o desenvolvimento de jogos baseados em realidade virtual são necessárias tecnologias específicas. Partindo do princípio de que imagens reais ativarão respostas do computador, a aquisição das imagens digitais por meio de webcams deve ser realizada de forma eficiente. Além disso, as imagens capturadas devem ser processadas de forma rápida para que os objetos ativadores sejam localizados, e as variações na posição e ângulos sejam interpretados para ativar os aplicativos do jogo. Todo processo deve ocorrer em tempo real.

Os aplicativos envolvem a utilização de computação gráfica e sons, que necessitam de processadores capazes de executar com eficiência suas instruções, enquanto o processo de reconhecimento das imagens da webcam continua a ser executado. Com relação ao reconhecimento das imagens, o processo envolve a webcam, que deve capturar as imagens com qualidade suficiente para a caracterização precisa do objeto ativador. Este objeto pode ser uma imagem com forma e cores específicas. Neste aspecto os recursos disponíveis no mercado atendem de forma satisfatória a necessidade de qualidade de imagem e velocidade de transmissão de dados. O reconhecimento de imagens de baixa e média complexidade podem ser realizados em frações de segundo em computadores dual core ( $2 \mathrm{~GB}$ de memória) por imagens adquiridas a partir de câmeras padrão caracterizadas por 30 quadros por segundo, e 1.3 megapixels de resolução ótica.

Quando a imagem digital de um quadro da webcam é transmitida ao computador, deve ser analisada por um software para que os objetos ativadores sejam identificados. Existem diversas possibilidades, entre elas softwares desenvolvidos a partir da plataforma Delphi (versões a partir da 5a), da empresa Borland software Corporation. As imagens devem ser transformadas em dados, que caracterizam cada um de seus elementos, os pixels. Cada pixel que compõe a imagem tem sua cor determinada por combinações de Vermelho (R), Verde (G) e Azul (B), o padrão RGB. Este padrão é usualmente baseado e 256 tons de cada cor base, formando mais de 16 milhões de combinações. Uma vez extraídos os tons RGB de cada pixel da imagem, devem ser empregadas técnicas de Processamento Digital de Imagens para realçar apenas os objetos de interesse, eliminando ruídos e objetos irrelevantes. A seguir o objeto de interesse deve ser classificado, e comparado com um banco de informações para sua identificação. O processo de classificação constitui uma área de pesquisa que envolve desde simples comparações até a utilização de inteligência artificial.

Uma vez concluído o processo de extração de informações da imagem, e a identificação do objeto ativador, o software de Realidade Aumentada insere em coordenadas específicas da imagem objetos de computação gráfica. Por exemplo, sobre a imagem de uma peça de tabuleiro com o desenho de um cavalo, pode projetar a imagem estática de um cavalo 3D, ou mesmo uma animação; sobre desenhos de orbitais 
químicos imagens 3D girando no espaço. O mesmo para imagens do sistema solar. Outro exemplo é a projeção de objetos 3D sobre a imagem da mão do usuário, girando e se deslocando de acordo com o movimento desta. Em termos específicos, cada componente necessário para produzir o efeito da Realidade Aumentada está disponível, sendo limitada ainda apenas em pequenos dispositivos móveis, como smartphones, onde a capacidade limitada de processamento restringe as aplicações, mas mesmo sem os recursos de um desktop, aplicações interessantes podem ser desenvolvidas. Além disso, estes dispositivos estão se tornado boas opções para jogos em RA (realidade aumentada) devido a rápida evolução das técnicas de seus processadores e sistemas operacionais.

\section{Realidade Aumentada em Jogos e Materiais na Educação Básica}

Nesse trabalho são descritas duas aplicações das técnicas de Realidade Aumentada em Jogos. Na primeira delas, é apresentado um jogo que trata da coleta de lixo num rio poluído, o usuário identifica o lixo no rio e com o auxilio de uma peneira ativada pela RA retira o resíduo e o despeja em coletor próprio. No segundo jogo, com o titulo Semear apresenta-se conceitos simples ligados à plantação: a planta escolhida para o tema é o girassol, esse jogo atende crianças da Educação Infantil e Ensino Fundamental I. A estrutura de apresentação e discussões para o desenvolvimento das etapas procurou seguir o roteiro elaborado por membros do projeto da área da Educação.

\subsection{ColetAR - Jogo sobre coleta de lixo baseado em Realidade Aumentada}

O tema propõe que o usuário identifique resíduos no rio e com o auxilio de uma peneira ativada através de uma Tag com o recurso da Realidade Aumentada, retire o lixo do rio e deposite-o no recipiente correto, os coletores seguem os padrões universais de relação cor/resíduo, durante o jogo há um marcador de tempo e de acertos. Inserido na temática ambiental, o jogo e as atividades complementares propõe uma analise sobre o poluir e suas consequências ao meio ambiente. A utilização da Realidade Aumentada visa incrementar o grau de interação entre programa e usuários. A abertura do sistema pode ser observada na Fig. 1.

O sistema mescla as imagens do mundo real capturadas por câmeras digitais acopladas ao computador e ao ambiente virtual. Seguindo o roteiro fornecido, os objetos virtuais desenvolvidos são inseridos no ambiente formando uma paisagem de fácil identificação (Fig. 2). A dinâmica do programa consiste em associar a um marcador (apresentados na seção anterior) uma rede que permite a captura dos objetos virtuais (garrafas, jornais, latas), e em seguida que estes sejam depositados na lixeira correta. 


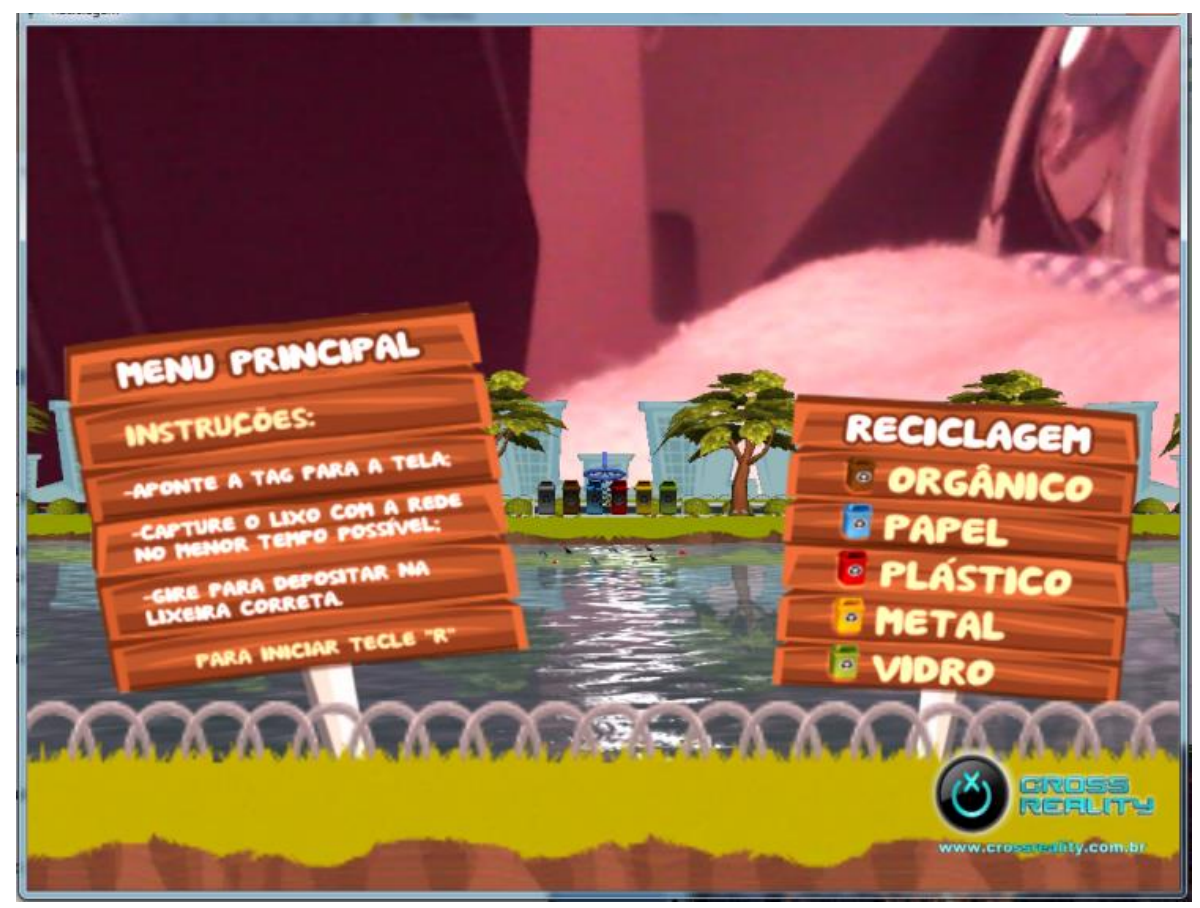

Figura 1. Imagem da tela principal do programa mesclando o ambiente virtual com a imagem capturada pela webcam do computador.

Com o reconhecimento do marcador pelo algoritmo, o sistema permite ao usuário movimentar a rede que captura os objetos utilizando projeções do espaço 3D para a tela do computador, ajustando o ângulo e tamanho do objeto de acordo com a posição deste marcador (Fig. 3). O sistema passou por diferentes etapas de desenvolvimento, de forma a permitir um resultado final fiel às recomendações do grupo do projeto encarregado da proposta educacional.

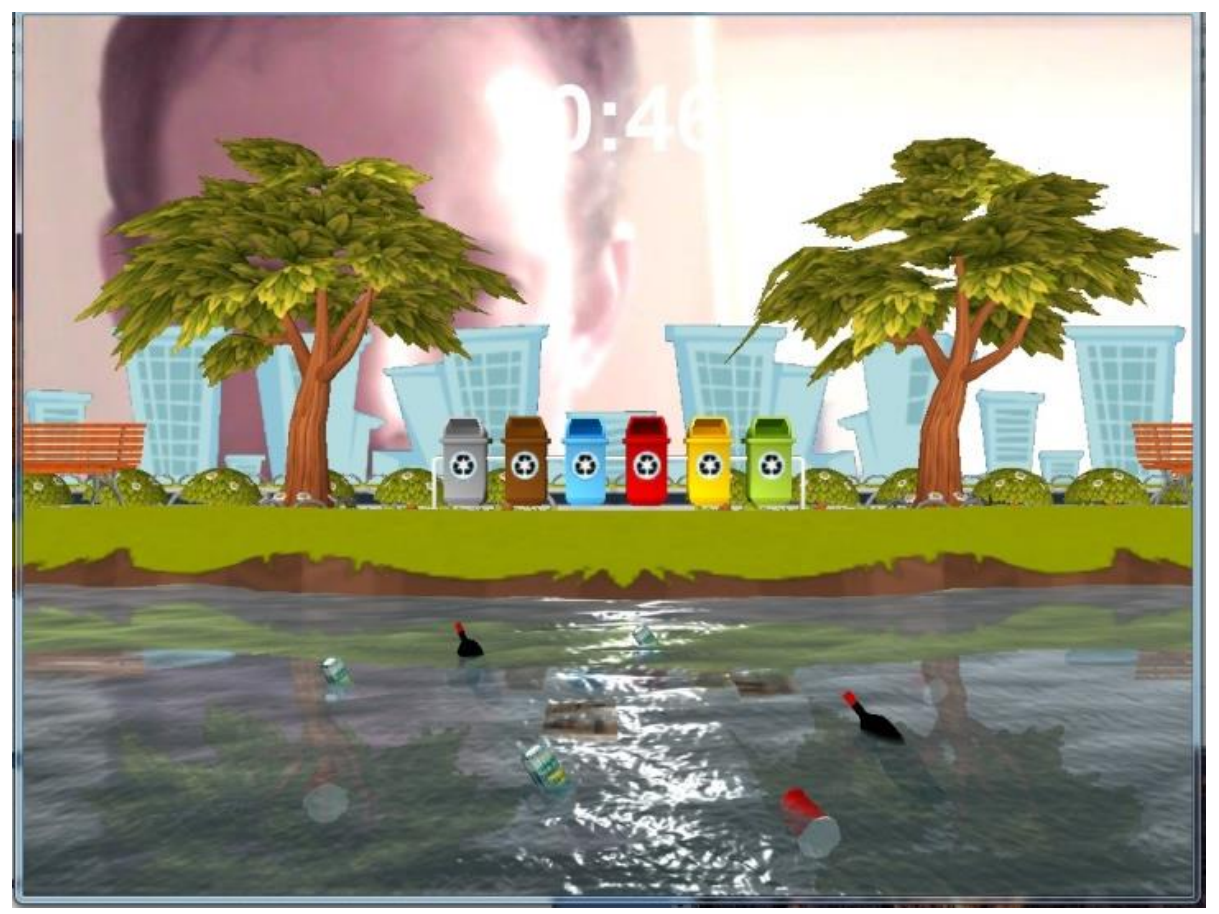

Figura 2. Ambiente para coleta de lixo reciclável 
As dificuldades técnicas que precisaram ser adequadas envolveram a correta identificação do marcador para que o usuário possa controlar o movimento da rede. Para isso o objeto rede foi associado a uma projeção frontal do marcador, e o movimento que permite depositar o objeto recolhido na lixeira foi restrito a um movimento bidimensional, enquanto que a captura destes objetos respeitou a estrutura tridimensional do ambiente. Ou seja, a rede/marcador tem três graus de liberdade na captura dos objetos, enquanto que o movimento (projeção da imagem) para depositar o objeto na lixeira é restrito a dois graus de liberdade.

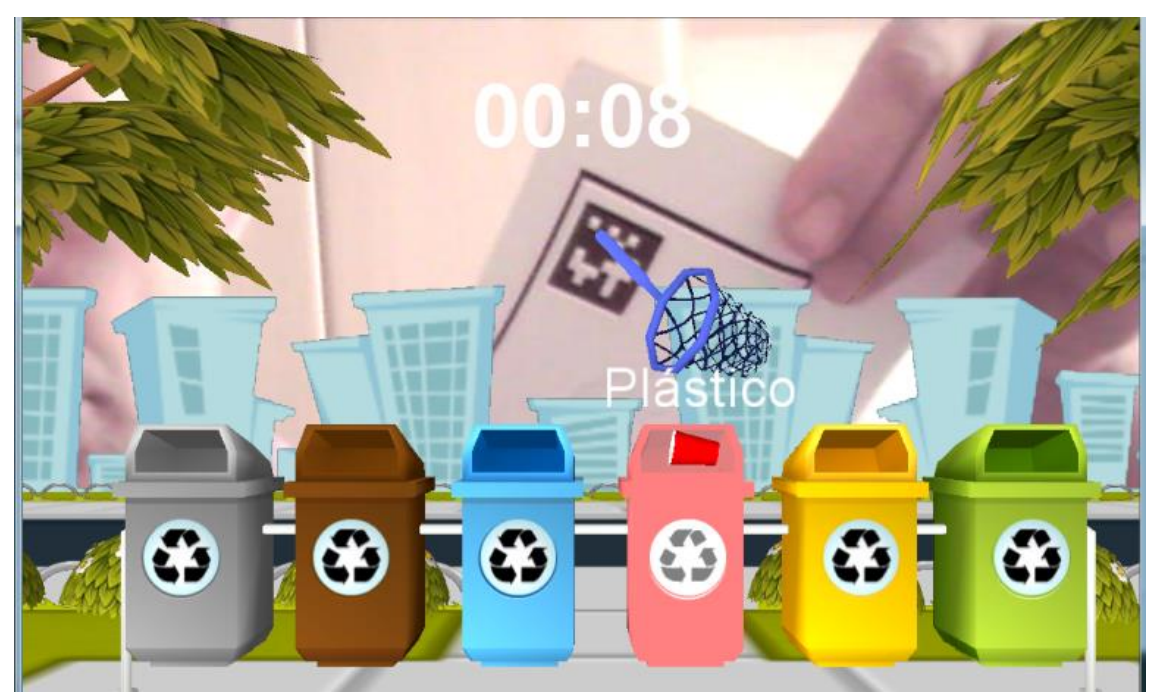

Figura 4. Rede de captura de objetos associada ao marcador.

\subsection{SemeAR - Jogo sobre a Semeadura de Girassóis}

O Jogo/Atividade chamado SemeAR deve ser proposto após levantamento do conhecimento prévio do grupo, problematizando os conceitos a respeito do processo de germinação e utilizando a atividade com base no recurso tecnológico da Realidade Aumentada para que a criança interaja virtualmente com as etapas da germinação e com o processo de transformação, conteúdo estruturante de ciências naturais. O jogo e as atividades complementares propostas visam:

- Desenvolver o interesse pela pesquisa;

- Familiarizar-se com o procedimento de pesquisa tecnológica e cientifica;

- Aproximar-se do conceito estruturante de transformação presente no processo de germinação;

- Vivenciar a transformação do real para o virtual e interagir virtualmente.

- Utilizar o procedimento do TAG (cartão) gerando imagens de Realidade Aumentada;

- Desenvolver a coordenação viso-motora através do uso do "TAG" e câmera de vídeo do computador gerando as imagens de Realidade Aumentada;

- Interessar-se pelas questões relativas à preservação do meio ambiente;

- Desenvolver sequência lógica dos fatos;

- Ler palavras-chaves dos TAGs e desenvolver a intertextualidade.

- Público Alvo: Crianças de 4 e 8 anos

O Jogo/Atividade é acompanhado de materiais impressos e orientações didáticas para os professores. Esses materiais fazem parte do projeto e foi construído como 
II Congresso Brasileiro de Informática na Educação (CBIE 2013)

Workshops (WCBIE 2013)

material complementar no intuito de contextualizar o conteúdo "germinação" em uma sequência didática ou como parte de pesquisa dentro da modalidade organizativa do tempo e espaço didático denominada Pedagogia de Projetos.

O ponto inicial do projeto foi a concepção do que denominamos Game Drifting (existem os conceitos de Game Design e Game Concept, mas nós preferimos cunhar um termo diferente, tendo em vista que ainda tratava-se de um protótipo em fase totalmente inicial e de brainstorming). Abaixo segue o roteiro do SemeAR proposto e discutido no início do projeto.

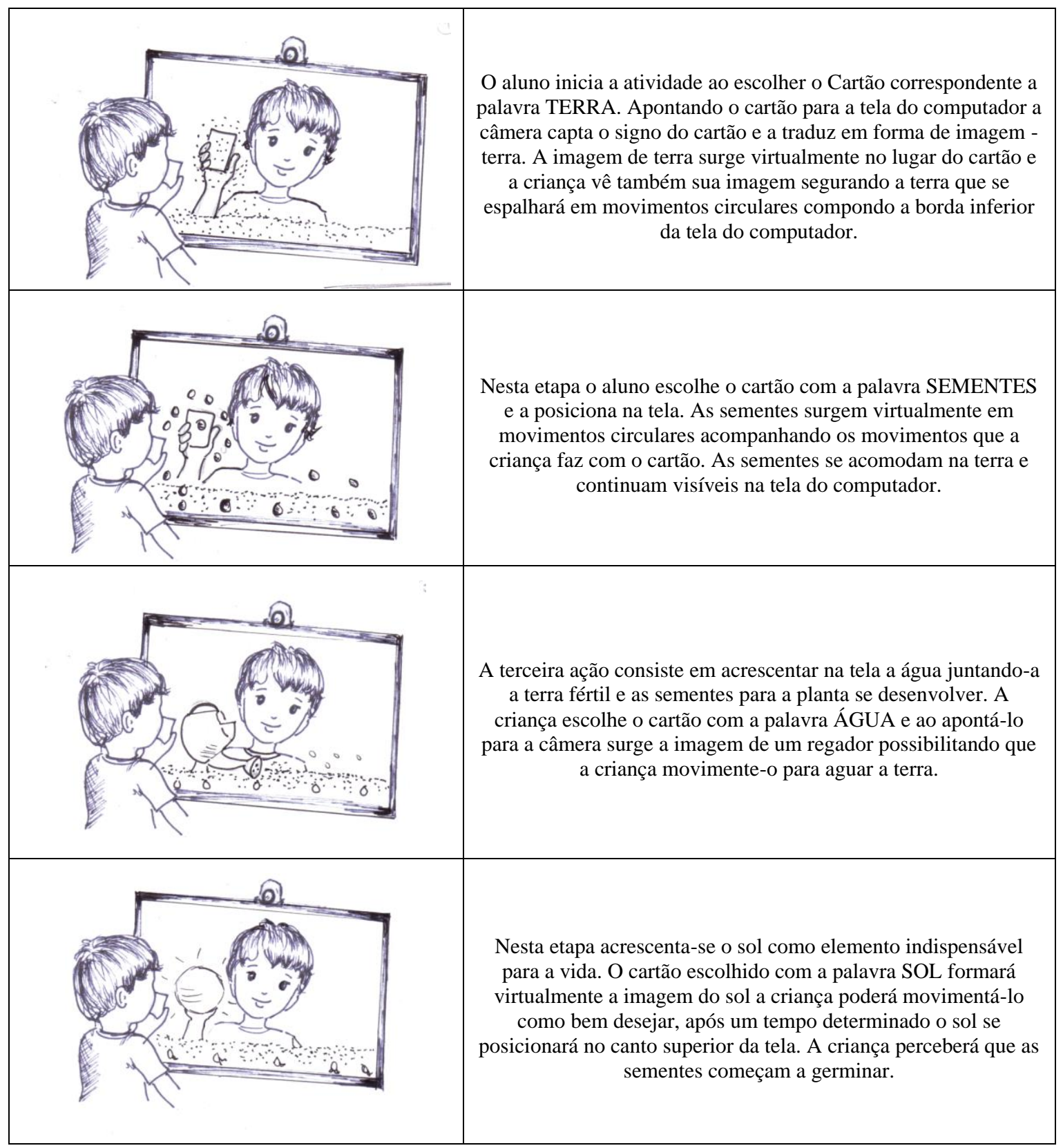


II Congresso Brasileiro de Informática na Educação (CBIE 2013)

Workshops (WCBIE 2013)

Na quinta etapa, com todos os elementos necessários para que
aconteça a germinação a criança aponta o cartão com a palavra
GERMINAR para a tela e a planta começa a crescer junto com o
aparecimento de algumas nuvens. Neste momento o movimento
que a criança fizer com o cartão será representado como vento na
imagem mexendo os elementos apenas de um lado para o outro
sem tirá-los dos lugares correspondentes.

O jogo SemeAR está disponível em versão para Web no endereço:

http://www.crossreality.com.br/semeAR/

Para jogá-lo basta imprimir as tags em:

http://www.crossreality.com.br/tags/tag-semear.pdf

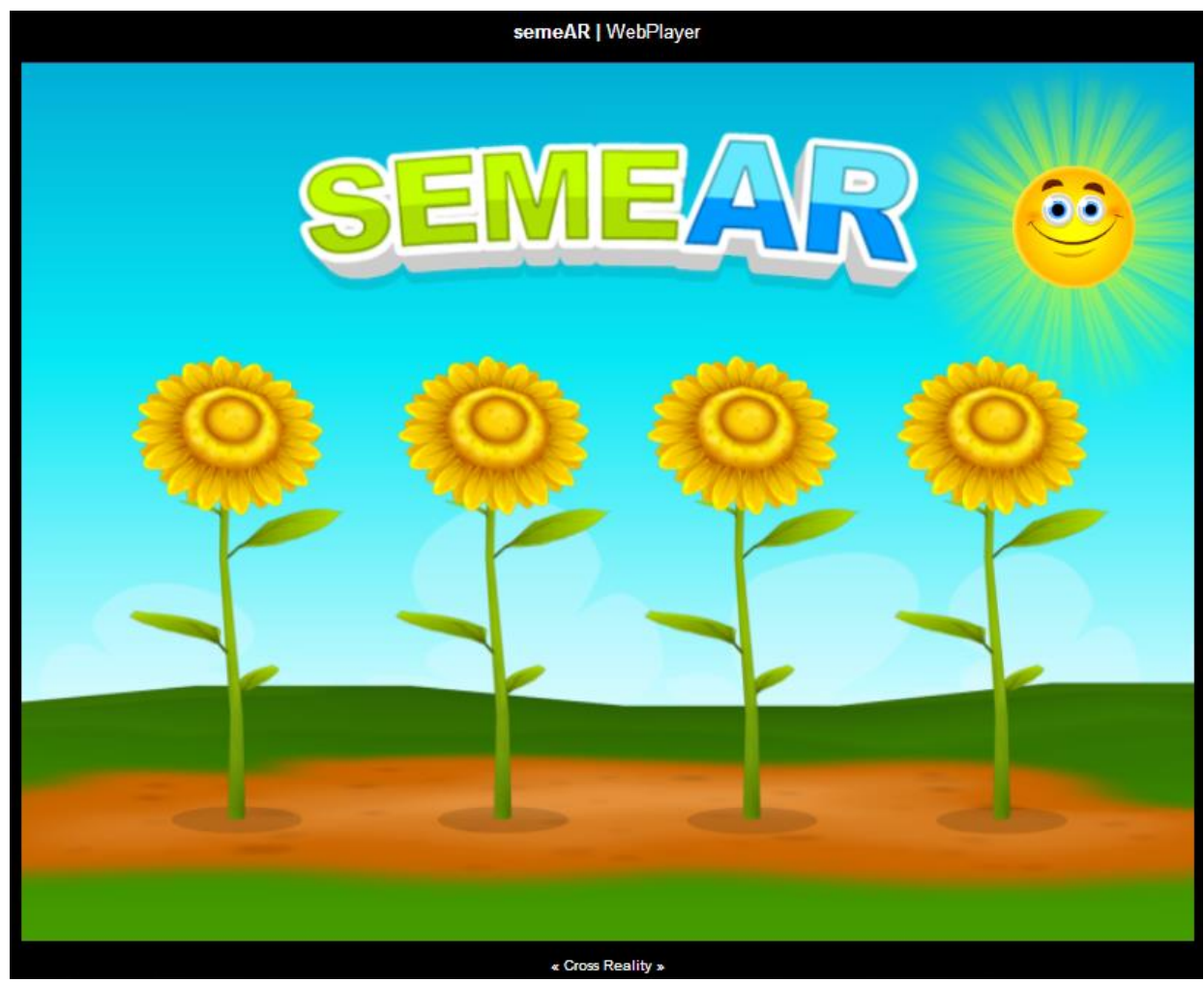

Figura 5. Tela de Abertura do SemeAR. 
II Congresso Brasileiro de Informática na Educação (CBIE 2013)

Workshops (WCBIE 2013)

O SemeAR passou por ajustes e modificações. Ainda, a motivação de criá-lo deu origem a outros jogos e atividades que submetemos em outro artigo. Além do jogo foram desenvolvidos materiais de acompanhamento que visam criar sinergia entre jogo/atividade, tarefas, instruções aos professores e alunos. Um exemplo é a figura 6.

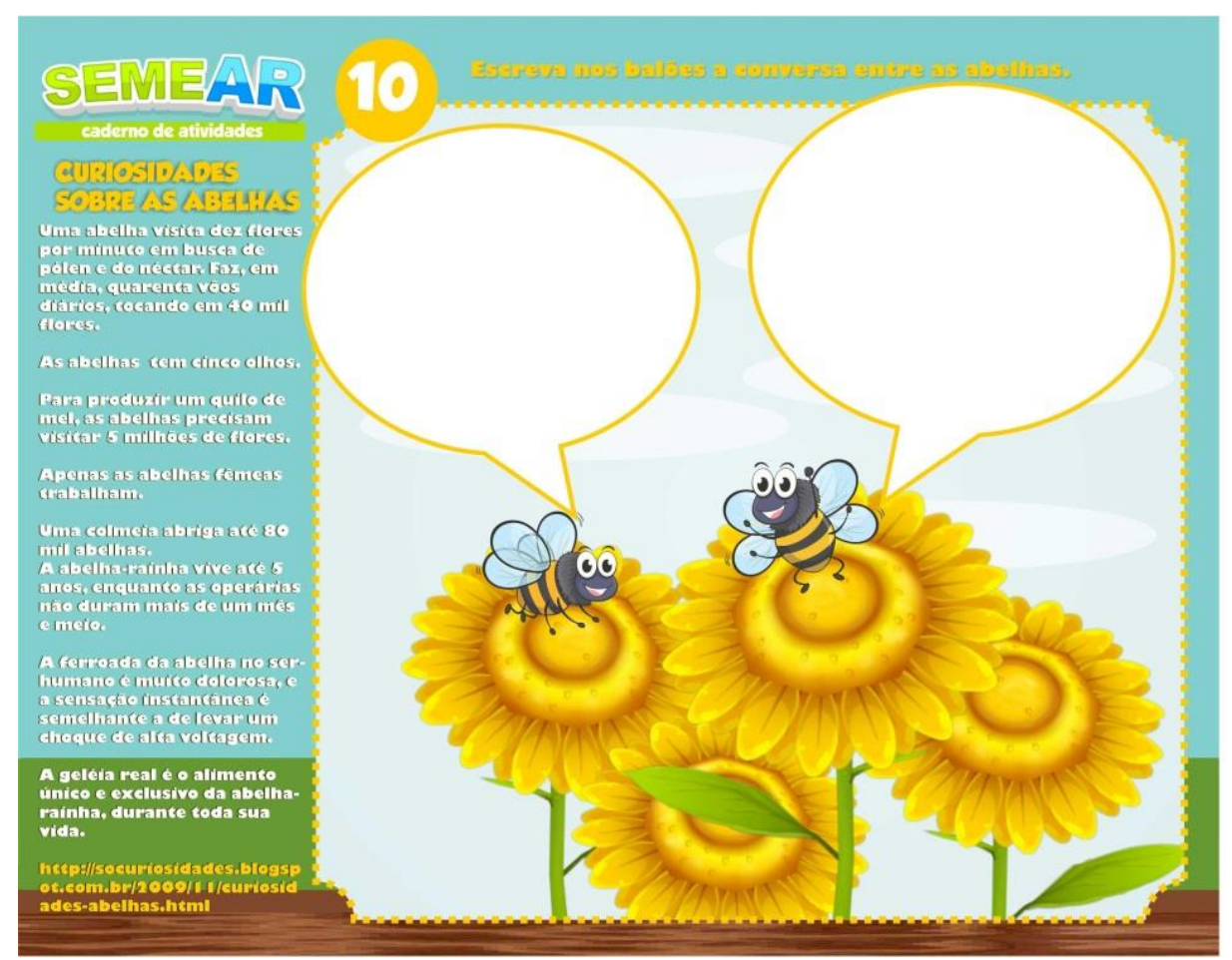

Figura 6. Exemplo de Atividade Complementar.

Já na figura 7 , há um exemplo de outra atividade complementar propondo a leitura, a apreciação e canto da música de Vinicius de Moraes e Toquinho.

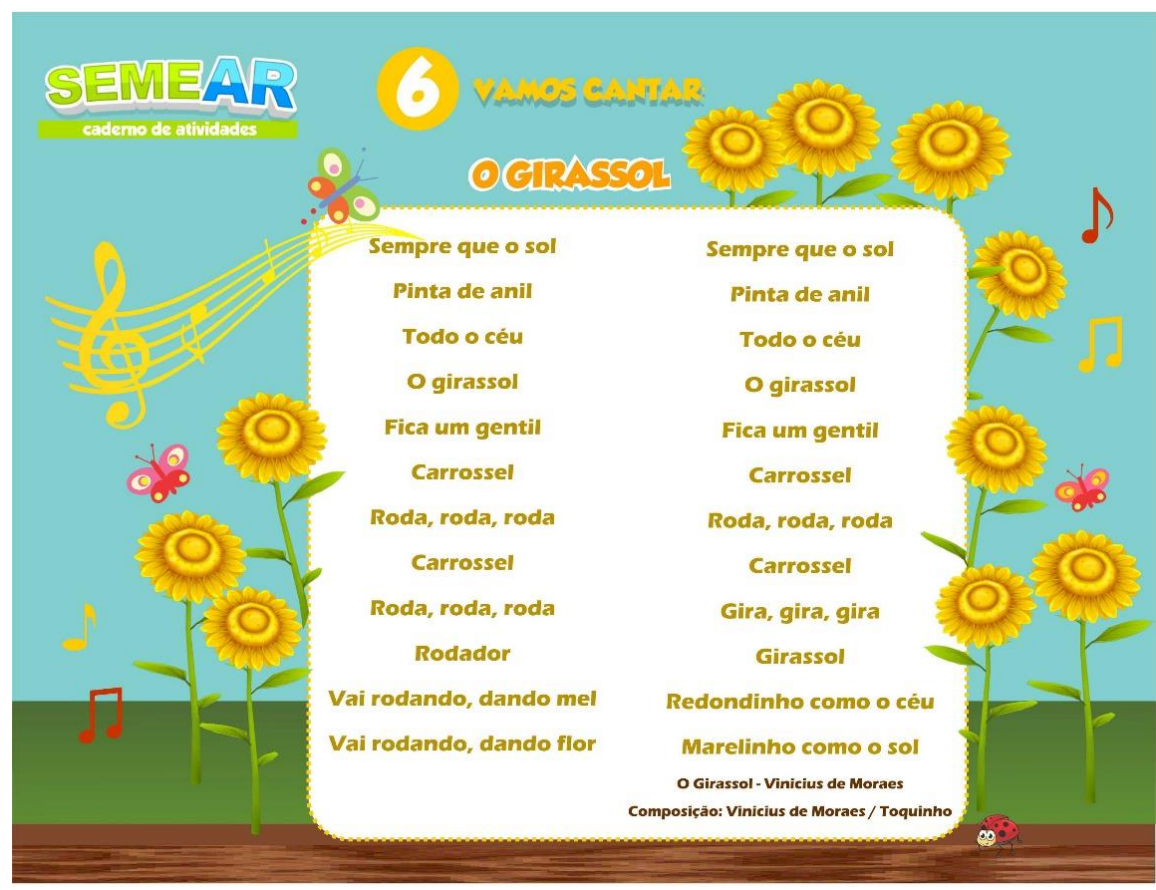

Figura 7. Exemplo de Atividade Complementar. 


\section{Considerações Finais}

O trabalho apresentado demonstra que a Realidade Aumentada pode ser aplicada como recurso pedagógico nas primeiras etapas da Educação Básica, oferecendo mais um caminho para a inserção digital, seguindo a premissa de que todos os recursos tecnológicos devam estar presentes nas escolas como meio de vencer o analfabetismo digital, inserindo as crianças num ambiente tecnológico, atual e apropriado à aprendizagem. Acreditando-se que a união de pesquisas e ações que visam o desenvolvimento educacional e tecnológico promovem nos alunos o exercício da cidadania.

\section{Agradecimentos}

Gostaríamos de agradecer ao CNPq por ter apoiado este projeto através do edital RHAE número 75/2010.

\section{Referências}

Azuma, R. (August de 1997). A Survey of Augmented Reality . Presence: Teleoperators and Virtual Environments, pp. 355-385.

El Sayed, N. A., Zayed, H. H., \& Sharawy, M. L. (Maio de 2011). Augmented reality student card: An augmented reality solution for the education field. Computers \& Education, pp. 1045-1061.

Milgram, P., \& Kishino, F. (1994). Taxonomy of Mixed Reality Visual Displays. EICE Transactions on Information and Systems, pp. 1321-1329.

Viegas, M. L., \& Silva, R. L. (2010). Ferramenta de apoio ao ensino de fisica utilizando Realidade Aumentada. Relatórios Técnicos do DCC/UFJF.

Yuen, S. C.-Y., YaoYuneyong, G., \& Johnson, E. (2013). Augmented Reality and Education: Applications and Potentials. (S. B. Heidelberg, Ed.) Reshaping Learning, pp. 385-414. 